\title{
Segmenting customers according to online word-of-mouth about hotels
}

\author{
Beatriz Moliner-Velázquez ${ }^{1} \cdot$ Maria Fuentes-Blasco $^{2} \cdot$ Irene Gil-Saura $^{1}$ (D)
}

Received: 30 June 2020 / Accepted: 31 December 2020 / Published online: 4 February 2021

(C) The Author(s), under exclusive licence to Springer-Verlag GmbH, DE part of Springer Nature 2021

\begin{abstract}
There is a renewed interest in the study of online word-of-mouth behavior due to the increasing use of the Internet and the development of social networks. This paper focuses on the receiver perspective to analyze the unequal influence of the antecedents of online consumer searches. The main purpose is to detect the heterogeneity of the effect of different motivations (convenience, risks reduction and social reassurance) and the volume of comments on the willingness to check online reviews. Based on 393 guests of hotels, a mixture regression model indicates the existence of three internally consistent segments, which reveal the varying influence on consumer intentions to look at online comments.
\end{abstract}

Keywords Online word-of-mouth $\cdot$ Motivation $\cdot$ Volume $\cdot$ Mixture regression model $\cdot$ Hotel $\cdot$ Unobserved heterogeneity

\section{Introduction}

Word-of-mouth behavior (hereon WOM) can be both a precedent and a consequence of consumers' evaluations. In the pre-purchase stage, individuals seek information as a risk reduction strategy (Flanagin et al. 2014), especially in the context of services; and in the post-purchase stage, consumers make and disseminate comments for several purposes such as help, revenge or to reduce cognitive dissonance (Laughlin and MacDonald 2010). Therefore, research on this behavior can be approached

Maria Fuentes-Blasco

mfuebla@upo.es

$\bowtie$ Irene Gil-Saura

irene.gil@uv.es

Beatriz Moliner-Velázquez

beatriz.moliner@uv.es

1 Department of Commercialization and Market Research, Universitat de València, Avgda. Dels Tarongers, s/n, 46022 Valencia, Spain

2 Department of Management and Marketing, Pablo de Olavide University, Seville, Spain 
from two perspectives: the sender or the receiver. Most studies have focused on the sender perspective (e.g. Harrison-Walker 2001; Berezan et al. 2015). However, fewer contributions have focused on WOM reception and its influence on purchasing decisions (e.g. Sweeney et al. 2008; Zhu et al. 2014), which is the approach adopted in the present work.

The growth in the use of Internet as virtual context has led to deep transformations in purchasing behaviors. One of them is the ease of consulting and sharing shopping experiences online. According to recent data, 77\% of Internet users conduct online consultations before deciding to buy (AIMC 2018). As a consequence of such a common practice today, WOM behavior in the online environment is of special interest to academics (Furner et al. 2016; Baber et al. 2016; Correia et al. 2017; Fine et al. 2017; Rani et al. 2018; Yusuf et al. 2018; Moliner-Velázquez et al. 2019) and companies (e.g. viral marketing, WOMMA, etc.). In the academic sphere, the influence of new technologies on shopping experiences is one of the main topics of interest according to the research priorities of the Marketing Science Institute for the 2018-2020 biennium. From the business perspective, the wide range of online shopping platforms and social media has contributed to the rapid development of the WOM industry.

In this context, tourism is one of the largest and fastest-growing economic sectors in the world (UNWTO 2018) and is closely linked to technologies. Hotel establishments, in particular, probably represent the activity that is most affected by the online WOM phenomenon (Serra-Cantallops and Salvi 2014). Hotel purchasing decisions are especially risky, both economically and functionally, since they are expensive services and the consequences are greater in case of dissatisfaction (Parikh et al. 2014). In addition, the fact that they are seasonal services that are difficult to assess before they are used leads consumers to seek information before making a booking to reduce the risks of their choice (Litvin et al. 2008). This entails that online WOM consultation highly influences the purchase process of these types of services. However, recent work has highlighted the problem that "democratization of opinions" can cause due to the unfiltered dissemination of online comments (e.g. Litvin et al. 2018). In this line of research, little empirical evidence exists as to the positive effects that eWOM inquiries have on purchase intentions in the hospitality industry (Kim and Lee 2015; Casado et al. 2017).

Although the literature on WOM behavior in hospitality is extensive, research gaps exists in the online environment and its effects on pre-purchase behavior. One question focuses on the motivations of consumers underlying online WOM behavior. Most studies have analyzed the motivations of consumers who write opinions (i.e. the focus is on the sender) (e.g. Shen et al. 2016; Xu 2018; Yen and Tang 2019) and a minority of studies focus on the consumer's reasons to consult and read comments (i.e. the focus is on the receiver) (e.g. Filieri and McLeay 2013). Contributions based on this latter perspective are few and no agreement has been reached as to the type of motivations that prompt online WOM consultations the most (Parikh et al. 2014). In this study, we thus focused on the receiver's perspective and examined the factors that motivate consumers to consult online WOM before purchasing. One factor that is closely related to the motivations for consulting online WOM is the volume of comments. The amount of online 
reviews of a product, service or brand is a sign of its popularity and interest in the market (Park and Lee 2009) and can motivate consumers to search for prepurchase information. Although many papers address the role of a hotel's volume of comments in purchasing decisions (e.g. Zhao et al. 2015; Matute et al. 2016), there is no empirical evidence of its effect on intentions to consult. Therefore, more contributions are needed to study the reasons consumers seek comments on the Internet to understand their relationship with online consultation behaviors.

In addition to addressing these gaps, it is important to integrate online WOM behavior into the company's marketing strategy. In this line, Litvin et al. (2018) highlight that in the field of hospitality management, segmentation is one of the strategies most affected by the changes derived from the proliferation of media and platforms favoring online communications among consumers (general networks such as Facebook, Twitter, Instagram, Myspace, Google +, or specific tourism sector networks such as TripAdvisor, Trivago, Expedia). These changes provide new opportunities for tourism market segmentation (Tsiotsou et al. 2012). It is thus essential to know consumers' online behavior in terms of their commitment to different media or the influence that these media have on their purchase decisions. Studies of online WOM behavior in hotels based on a heterogeneity analysis are scarce and focus mainly on describing segments of consumers who write comments (e.g. Xu and Li 2016; Xiang et al. 2017; Wu et al. 2017; Dowell and Turner 2019).

In summary, the limitations identified in the literature are: (a) most research on motivation focuses on the sender's approach; (b) a lack of results on the possible effect of online WOM motivations and volume on pre-purchase inquiries; and (c) limited research on market heterogeneity based on online WOM query behavior. We thus raised the following questions: what types of motivations weigh the most in online WOM consultation behavior? How does the volume of online WOM influence pre-purchase inquiries? And to what extent are the consumers who consult online WOM heterogeneous? Therefore, the key themes when studying the behavior of online WOM from the receiver's perspective are: the motivations to consult online WOM, the volume of online WOM, and consumer heterogeneity.

Based on these challenges, this paper focused on the effect of the proposed antecedents and examine consumer heterogeneity in online WOM hotel consultations. Specifically, the objectives of the study are as follow:

(1) To study the influence of the following two variables on the intention to consult online WOM: a variable associated with the consumer-the motivation of the individual represented in three types of motivations (convenience, risk reduction and social reassurance) (Kim et al. 2011) — and a variable associated with the purchasing decision, that is, the volume of comments on a particular hotel.

(2) To analyze the unobserved heterogeneity, regarding the relations between the motivations and the volume on the intention to consult online WOM, using regression mixture modeling that allows to simultaneously estimate the effects and identify segments of consumers. 
(3) To describe the resulting segments based on socio-demographic criteria (gender, age, educational level and nationality) and experience-related variables (type of trip and frequency of visit).

The novelty of this study therefore lies in both the analysis of these variablesmotivations and volume - as antecedents of the online WOM queries and the analysis of the market's heterogeneity based on this behavior. The results will allow obtaining relevant conclusions from an academic and practical viewpoint. Academically, progress will be made in the study of online pre-purchase WOM behavior and segmentation based on criteria related to consumer behavior online. At a practical level, the results can help company managers to adapt strategies relating to the effect of online WOM consultations on accommodation purchasing decisions. First, it will be possible to identify which types of motivation influence the intention to consult online reviews and what role is played by the volume of comments on a hotel. In addition, it will be possible to discover differences in these effects according to the heterogeneity of the consumers and the profiles of the resulting segments.

\section{Literature review}

\subsection{WOM behavior}

WOM behavior is one of the most relevant and recognized dimensions of loyalty. Although literature on the subject exists since the 1960s, it has recently attracted special interest at the academic level (Serra-Cantallops and Salvi 2014). The theoretical review shows that conceptual and operational disagreements persist, and that this field of research still presents challenges and unresolved issues.

The most widely used definitions of WOM are shown in Table 1. One can observe disagreements on the consumer's role in the information exchange (sender, receiver, or both) and the means used to transmit WOM (personally, online, or indifferent). In addition to these disagreements, the following issues are also subject of debate: the content of the information (recommendation, comments, or both), the credibility of personal (or traditional) WOM and online WOM; and the range of behavior dimensions (Table 2).

Regarding the consumer's role (Table 2), Harrison-Walker (2001) and Theng and $\mathrm{Ng}$ (2001) describe how communication is performed directly and personally since the sender is a non-commercial communicator (consumer) (Table 1). Following this approach, it is agreed that the transmitted message is more real and credible than that of advertising (Litvin et al. 2008) since it is independent of the company and has no interest in embellishing the truth in favor of the product (Silverman 2001). If the sender is the consumer, a debate arises as to whether this behavior could also include customers' communication to companies in the form of complaints, suggestions or congratulations (Mazzarol et al. 2007). Other authors, however, emphasize that the sender and the receiver of the communication are consumers (Anderson 1998; Silverman 2001; WOMMA 2014) (Table 1). These disagreements are also reflected in the scant definitions of online WOM. Hennig-Thurau et al. (2004) also 


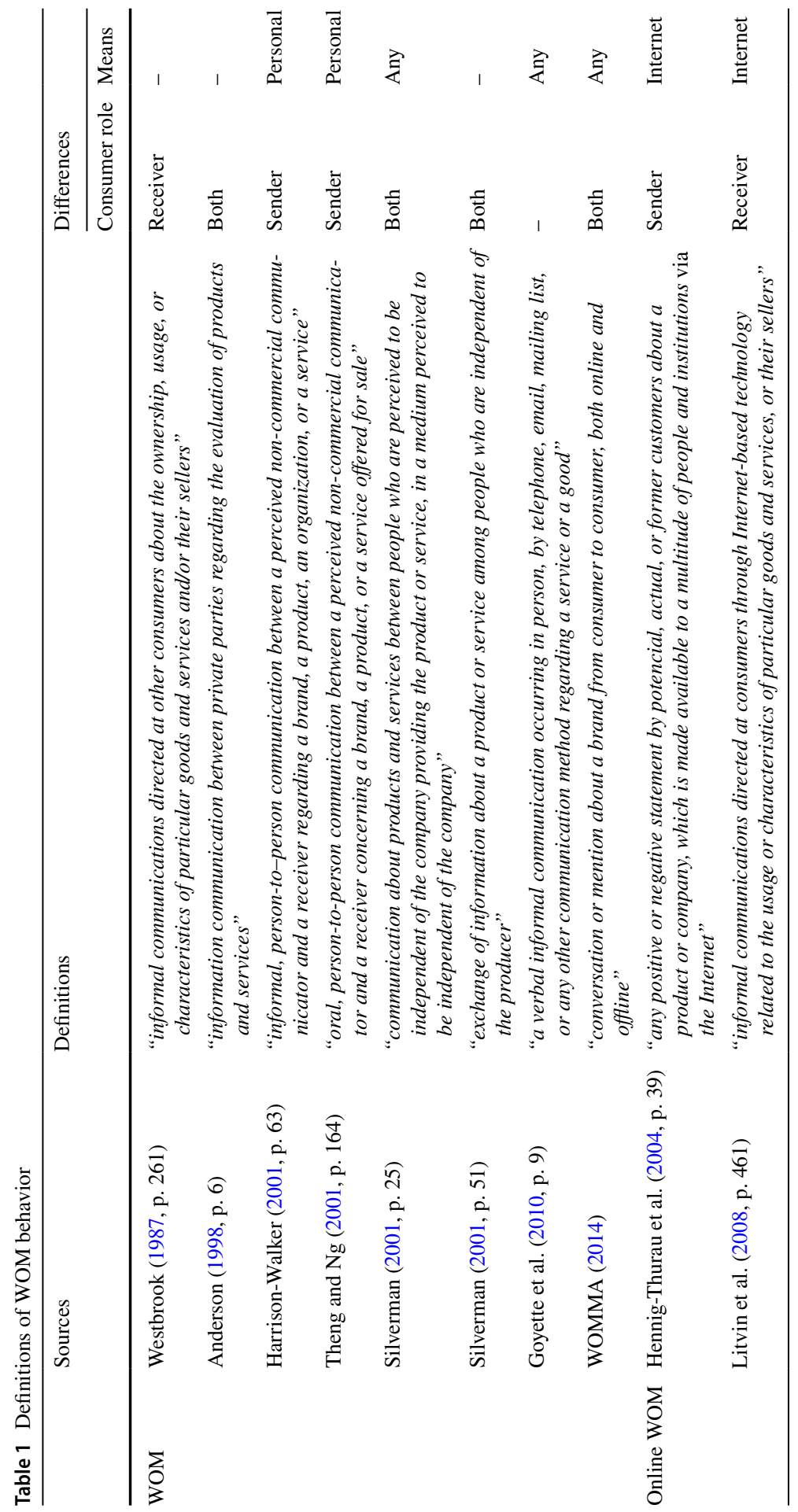




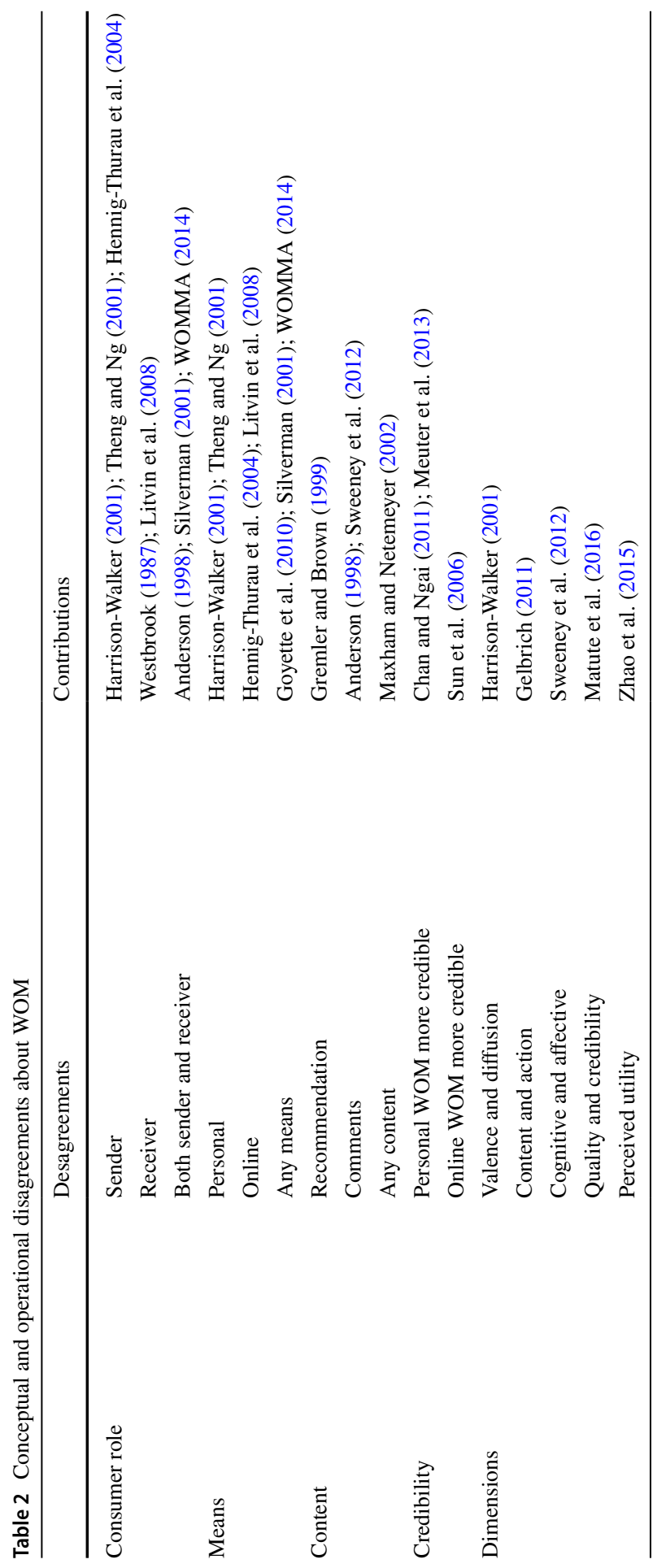


highlight that the sender is the consumer, while Litvin et al. (2008) point out that the receivers are the consumers. In both cases, it is understood that online WOM behavior includes not only communications between consumers but also between companies and consumers. In the latter case, it can be understood that online promotion or advertising (company to consumer) and online complaints or suggestions (consumer to company) are online WOM. It could also be considered that viral marketing is a way of developing online WOM. Therefore, the role played by the consumer in the communication may condition the study's approach (sender or receiver) and the difference between WOM behavior and other related constructs.

With regard to the means used to transmit the information (Table 2), unlike some definitions that do not refer to any medium, Harrison-Walker (2001) and Theng and $\mathrm{Ng}$ (2001) propose that the medium is personal, while Silverman (2001) highlights that the medium is independent of the company. However, Goyette et al. (2010) describe different ways of disseminating information: WOM behavior would thus be of a general nature and would also include WOM disseminated through the Internet (WOMMA 2014) (Table 1). In fact, some authors consider that online WOM is an extension of traditional WOM (Yeap et al. 2014). This question is especially relevant to understand to what degree both constructs should be differentiated. In this line, the literature identifies clear differences between personal and online WOM (e.g. Sun et al. 2006; Berezan et al. 2015; Furner et al. 2016; Bachleda and BerradaFathi 2016), related above all to the scope, speed, availability of information and the variety of online media.

Moreover, there is a lack of consensus over the message transmitted through WOM behavior (Table 2). Some authors consider it to be an active recommendation made by consumers (e.g. Gremler and Brown 1999); some view it simply as a comment on a product or service (e.g. Sweeney et al. 2012); some emphasize that the behavior refers to extremely positive or negative comments on memorable experiences (e.g. Anderson 1998); while others argue that it is a combination of comments and recommendations (Maxham and Netemeyer 2002). More recently, Terblanche (2016) conducted a research on this topic to compare the content of WOM evaluating the intention both to share the experience and to recommend. They conclude that measuring WOM through recommendation should be reconsidered since it does not really reflect the consumer experience. Therefore, if loyalty is a general construct containing WOM, among other variables, resolving the issue about information content is key to decide whether this behavior is a dimension of loyalty.

Regarding the credibility of the information transmitted during online and personal WOM behavior (Table 2), the debate about which of the two behaviors is more credible and more influential on purchasing decisions is also relevant when seeking to differentiate the nature of both constructs (Bachleda and Berrada-Fathi 2016). In this question, King et al. (2014) emphasize that online WOM is a powerful source of information mainly due to the volume and dispersion of comments, the persistence and observability of the information, as well as the anonymity and the social commitment it generates. Some authors consider that online WOM is less credible than personal WOM as consumers exchange opinions with people they do not know from anywhere in the world (e.g. Chan and Ngai 2011; Meuter et al. 2013). However, other authors point out that online WOM is more reliable due to its speed, 
convenience, reach, and absence of the pressure that is inherent to face-to-face interactions (e.g. Sun et al. 2006).

Finally, from an operational viewpoint, given the broad range of dimensions that constitute the WOM, there is also a disagreement as to which components allow measuring this type of behavior (Table 2). WOM has been traditionally characterized as having a two-dimensional nature: the evaluative (valence or goodness of the message: positive vs. negative) and the conative (degree of dissemination of the information) dimensions (e.g. Harrison-Walker 2001). Other works consider new dimensions, such as content and action (e.g. Gelbrich, 2011) or cognitive and affective components (e.g. Sweeney et al. 2012). More recent contributions analyze other characteristics such as the quality and the credibility of the message (e.g. Matute et al. 2016), the perceived utility of WOM (e.g. Zhao et al. 2015) or the sentiment (e.g. Song et al. 2016; Buzova et al. 2019). In addition, considering the differences between personal and online WOM, the form of information dissemination can be added to these dimensions. Despite the debates on WOM measurement, most online WOM studies consider this behavior as a single-dimension construct (e.g. Boo and Kim 2013). However, the two-dimensional approach of Harrison-Walker (2001) has also been accepted in the context of hotels (Casaló et al. 2015; Yen and Tang 2019). For example, Yen and Tang (2019) operationalized online WOM behavior based on four dimensions: intention, frequency, thoroughness, and praise.

Considering all these disagreements regarding the conceptual delimitation of WOM behavior (Table 2), the definition adopted in the present study is based both on the dual role of the consumer (sender and receiver) of Anderson (1998), Silverman (2001) and WOMMA (2014), and the approach to the use of different information transmission media supported by Goyette et al. (2010), Silverman (2001) and WOMMA (2014). Accordingly, we understand that online WOM behavior is any type of comment about a product, service or shopping experience that is consulted or produced by consumers through any communication method.

\subsection{Motivations to consult online WOM}

The literature agrees that consumer comments about a service can be a powerful form of promotion, since they have a marked capacity to influence the purchasing decisions of other consumers (Litvin et al. 2008). Several works show how consultations have an impact on the knowledge and services sales (e.g. Park and Lee 2009). In the context of hotels, online WOM consultations can even override the influence of other sources of information (O'Connor 2009). However, this behavior is not in itself sufficiently effective, since the information's receiver must react positively after receiving it (Sweeney et al. 2008). Therefore, some of the individual's internal variables, such as motivations, become key elements to understand why consumers consult online WOM (Kim et al. 2011).

Most of online WOM motivations studies addresses consumers' motives for writing reviews (e.g. Bigné et al. 2015; Lin and Xu 2017; Kim and Jang 2019). Contributions that treat motivations for consulting are not abundant and, in addition, it is possible to detect disagreements among them. The earliest proposals 
were developed by Schiffman and Kanuk (1978), who identified three motivations: self-involvement, involvement with the product and involvement with others. According to this approach, Hennig-Thurau and Walsh (2003) proposed a set of reasons related to risk, purchase security, reduction of dissonance, a social component and product learning. To these motivations, Goldsmith and Horowitz (2006) summate reasons related to the convenience and timeliness of the found information and Parikh et al. (2014) add the search for novelty and trust in the consultations. More recently, Srivastava and Kalro (2018) conducted a literature review and suggested that the key factors that motivate consumers to seek online WOM were: better decision-making, risk reduction, to counteract the negativity bias, social reasons, curiosity, economic incentives and validation of existing beliefs were.

In short, one of the most recognized classifications in the literature is that of Kim et al. (2011). Combining the results of representative contributions such as HennigThurau and Walsh (2003) and Goldsmith and Horowitz (2006), they collect the three following types of motivations:

(1) Convenience motivations or reduction of evaluation and information search efforts (Goldsmith and Horovitz 2006): when individuals seek information, they incur internal costs (mental effort to classify and integrate the information) and external costs (opportunity cost of the time dedicated to the search and monetary cost of acquiring the information) (Smith et al. 1999). Consumers are motivated to consult online WOM because they want to avoid time-consuming search tasks, the unbiased information they find allows them to reduce cognitive dissonance, they seek to get the best value for the money spent, and finally Internet is easy to use and very accessible (Hennig-Thurau and Walsh 2003).

(2) Motivations of risk reduction of purchase (Kim et al. 2011; Sweeney et al. 2008; Flanagin et al. 2014): consumers perceive four types of risk when faced with a decision (functional, social, financial and physical) (Mitchell and Greatorex 1989) that encourages them to seek information to mitigate the intangibility, inseparability, variability and perishability of services (Lin 2008) and, therefore, to decrease the probability of a purchase failure (Parikh et al. 2014). In the tourist context, functional risk is related to the benefits of the service sought by the consumer (e.g. comfort), social risk reflects the degree of acceptance of others (e.g. family rejection), financial risk is linked to price (e.g. deception) and physical risk represents the perceived dangers affecting the consumer's physical integrity (e.g. terrorist act) (Carballo et al. 2017).

(3) Social reassurance motivations or search for safety and social approval (Abrantes et al. 2013; Parikh et al. 2014): groups are able to influence their members' opinions due to the social pressure derived from the effect of conformity (Lee et al. 2011). According to this effect, individuals join the majority opinion even when they are not physically present (Kaplowitz et al. 1983), as is the case in the virtual environment. In this line, consumers like to be part of virtual communities, interact with other consumers and share information. These motivations seek to satisfy not only the need to belong but also curiosity about new products on the market or learning about products (Hennig-Thurau and Walsh 2003). 
The proposed conceptual model

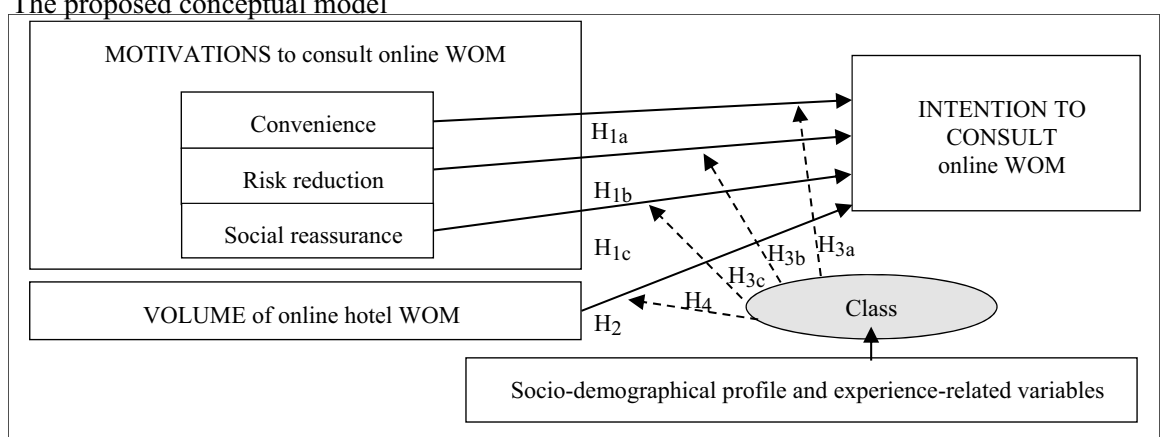

Fig. 1 The proposed conceptual model

We selected the classification of Kim et al. (2011) because their proposal is the one that best reflects and summarizes the different motivations described in the literature. Furthermore, these three dimensions adequately collect the different reasons that move consumers to make online WOM inquiries in the hospitality context.

Studies on the effects of motivations to consult online WOM before purchase are scarce. Some papers analyze their relationship with the purchasing decision (e.g. Parikh et al. 2014) or with some consumers' socio-demographic characteristics (e.g. Kim et al. 2011). For example, Parikh et al. (2014) conclude that consumers' motivations when they consult online WOM are social and altruistic, but they do not address how these motivations influence the intention to consult. No empirical evidence has been found on the effect that motivations have on online WOM search behavior. Based on the previous research, the three types of motivations (convenience, risk reduction and social reassurance) (Kim et al. 2011) will be considered significant antecedents of online WOM consultations of hotel establishments (Fig. 1), leading to the first raised hypothesis:

$\mathrm{H}_{1} \cdot \mathrm{H}_{1 \mathrm{a}}$ ) Convenience motivations $\mathrm{H}_{1 \mathrm{~b}}$ ) risk reduction motivations and $\mathrm{H}_{1 \mathrm{c}}$ ) social reassurance motivations have a positive impact on the intention to consult online WOM about hotels.

\subsection{Volume of online WOM}

The volume or quantity of information is a major component of WOM behavior and refers to the number of comments disseminated over the Internet (Zhu and Zhang 2010). This degree of diffusion can be considered as a popularity factor that reflects the market's interest in a product (Park and Lee 2009). Some researchers argue that this variable makes information more objective, improving the confidence of consumers who consult it ( $\mathrm{Hu}$ and Kim 2018). In addition, the utility perceived by the user can increase, since it has a greater quantity and variety of information (Park and Lee 2009). This allows to reduce the risk and help to make more rational decisions.

The effect of the volume of comments on consumer behavior can be derived from the theory of Petty and Cacioppo (1986), which is widely used in online 
WOM literature (Chan and Ngai 2011). According to this approach, when consumers receive information that helps them make their decisions, they might follow the central or the peripheral route according to their level of involvement. If consumers are highly involved in the product/service, they will be more likely to use the central route, that is, they will be influenced by the information's quality. If the consumers are less involved, they will be more likely to take the peripheral route, being influenced by aspects that require cognitive effort such as the image of the product or the amount of information. Several works support this theory by pointing out that the volume of information is especially taken into account by consumers who are less involved or less able to process the message (Gupta and Harris 2010).

Generally, research on this variable analyzes its relationship with aspects linked to the purchasing decision. For example, some authors have found a correlation between the volume of comments and sales in the services sector (e.g. Zhu and Zhang 2010), while others have failed to find significant effects (e.g. Davis and Khazanchi 2008). Furthermore, some empirical evidence in the accommodation sector is contradictory or difficult to compare. Some authors have concluded that the number of opinions does not influence the usefulness of online comments in the purchasing decision (e.g. Filieri and McLeay 2013). On the contrary, the majority point out that the volume can have an effect on bookings, since it is related to the consumers attitudes (Wang et al. 2007), to the average rating of the comments (Blal and Sturman 2014), to the usefulness of the valuations and the intention to return (Matute et al. 2016), to the intention of booking (Zhao et al. 2015) and to trust in the consultations (Furner et al. 2016).

Based on these works, a certain disparity can be detected in the results as well as a lack of agreement regarding the variable that the volume has an influence on. However, they suggest that the volume of WOM may have some influence on consumers' consulting behaviors. No empirical evidence has been found in the hospitality context on direct effects. Taking this gap into account, it is understood that the consumers' perceptions of a hotel's WOM volume will encourage them to make online consultations because disposing of more and more varied information will increase trust and reduce their purchasing risks (Yen and Tang 2015; Park and Lee 2009). The following hypothesis is formulated (Fig. 1):

$\mathrm{H}_{2}$. The volume of a hotel's online WOM has a positive impact on the intention to consult online WOM.

\subsection{Heterogeneity in the online WOM consults}

The segmentation literature related to online WOM behavior in hospitality is very scarce. The contributions identify differences in the comments written by tourists based on several variables, such as their nationality (e.g. Liu et al. 2017), the online platform used (e.g. Xiang et al. 2017), the language style (e.g. Wu et al. 2017), the type of hotel (e.g. Xu and Li 2016) or the type of tourist (e.g. Xu 2018). These studies have substantial limitations. On the one hand, they study this behavior from the point of view of the information sender, but an individual's motivations to write online comments can be very different from those that one can have when 
consulting them. On the other hand, they analyze how online comments written in groups established a priori differ.

To advance in this line, the present study seeks to find segments where consultations undergo an uneven influence due to the heterogeneous evaluation of antecedents. If previous works have revealed that the performed WOM behaviors varied according to different consumer groups, behaviors regarding the consultation of WOM may also differ according to certain variables. In this sense, the literature somewhat indicates that some relationships linked to online consultations may vary. It is assumed that the effect of motivations and volume on the intention to consult will be different according to the consumer group, and the following hypotheses are proposed:

$\mathrm{H}_{3}$. The strength of the relationship between $\mathrm{H}_{3 \mathrm{a}}$ ) convenience motivations, $\mathrm{H}_{3 \mathrm{~b}}$ ) risk reduction motivations and $\mathrm{H}_{3 \mathrm{c}}$ ) social reassurance motivations and the intention to consult online WOM is different according to the consumer segment.

$\mathrm{H}_{4}$. The strength of the relationship between the volume of a hotel's online WOM and the intention to consult online WOM is different according to the consumer segment.

Figure 1 illustrates the previous relationships, assuming the existence of latent segments resulting from unobserved heterogeneity. In addition, this proposal uses socio-demographic information and variables that characterize the experience as segmentation covariates.

\section{Methodology}

\subsection{Measurement instrument and field work}

To test the proposed model, quantitative research applied to hotel services was conducted using personal surveys. Data were collected through a structured questionnaire with closed questions measured using 7-point Likert scales (Table 3).

The fieldwork was carried out in the Valencian Community (Spain). The main population under study comprised hotel guests located in this geographical area. Hotels in two Spanish cities in Valencia province were considered: Valencia and Gandía. Valencia is the third biggest city and one of Spain's top tourist destinations. It represents the country's general profile, being both a leisure and business destination. Gandia is a top destination for "sun and beach" tourism in the province. A starting census was drawn up, identifying the hotels from the Official Guide of hotels in Spain ${ }^{1}$ and the directory of hotels of the Valencian Tourism Agency. ${ }^{2}$ This information was completed with that of the SABI (Iberian Balance Sheet Analysis System) and DUNS100,000 ${ }^{3}$ databases. From the resulting list, two 5-star hotels,

\footnotetext{
${ }^{1}$ Copy edition 2009 and successive updates available at: http://www.tourspain.es/es-es/Paginas/index .aspx

${ }^{2}$ http://comunitatvalenciana.com/viaje/alojamiento/hoteles

${ }^{3}$ http://www.duns100000.com
} 
Table 3 Measurement scales

\section{Motivations to consult online WOM \\ Adapted from Kim et al. (2011) and based on Hennig-Thurau and Walsh (2003) and Goldsmith and Horowitz (2006)}

Convenience

Risk reduction

Social reassurance

\section{Volume of online hotel WOM}

Adapted from Matute-Vallejo et al. (2015) and based on Park et al. (2007) and Belanche et al. (2013)

\section{Intention to consult online WOM}

Adapted from Leung et al. (2015) and based on Chiang and Jang (2006) and Gruen et al. (2006)
"I read information about hotels from other consumers' online reviews...":

Because it's the fastest way to get information

Because it's convenient to search from home or work

Because I am able to compare different hotels easily

To find solutions for my problems

Because customer reviews help me to make the right buying decisions

To benefit from others' experiences before I book a hotel room

Because I like being part of a community

Because I enjoy participating in the experiences of other community members

Because I get to know which topics are in

This hotel has many online recommendations and reviews from other users

The volumen of opinions on this hotel is very high

Many consumers write their comments and ratings about this hotel

The probability that I would consider consulting online reviews in ... is very high:

Social media (Facebook, Twitter, etc.)

Metasearch engines (Tripadvisor, Booking, Kayak, Trivago, etc.)

Web pages of the hotels

Other electronic media (email, WhatApp, Telegram, WeChat)

twenty two 4-star hotels and eighteen 3-star hotels were selected in Valencia (29 hotels located in the central and maritime districts were investigated) and Gandia (13 hotels). Corresponding authorizations were requested to carry out interviews in the hotel reception areas and in the access areas. The data were collected in hotel lobbies through personal interviews to the guests who were selected according to their availability to participate in the research without any pressure and who were willing to sign the consent form that the data can be used for publication. A nonprobability convenience sampling approach was used in this study. A total of 1,175 
potential respondents were addressed, obtaining 393 valid and complete questionnaires, thus achieving a response rate of $33.45 \%$. Specifically, 151 guests stayed in 3 -star hotels (38.4\%), 227 guests in 4-star hotels (57.8\%), and 15 guests in 5-star hotels (3.8\%). The main characteristics of the sample are shown in Sect. 4.2.

\subsection{Dimensionality, reliability and validity of the measurement scales}

The preliminary dimensionality study was conducted via an exploratory factor analysis. Based on the $\alpha$-Cronbach reliability index, the item "The probability that I would consider consulting online reviews in other electronic media is very high" was removed from the intention to consult scale. The dimensionality was confirmed with a first-order measurement model with Robust ML estimation, where all items properly loaded on each of the five latent factors relating to convenience, risk reduction, social reassurance (motivations to consult), volume of online hotel WOM and intention to consult online WOM (all standardized factor loadings were significant and higher than 0.6). Considering with caution the significance of the global contrast sensitivity to the sample size (Hair et al., 2008, pp. 680-681), the statistics indicated that the model showed an adequate fit $\left(\mathrm{Chi}^{2}{ }_{\text {Sat-B }}(\mathrm{df}=94)=279.69\right.$; RMSEA $=0.073$, CFI $=0.952$, IFI $=0.952$, GFI $=0.898, \quad B B-N F I=0.931$, BBNNFI =0.937). The internal consistency was evaluated through the composite reliability (CR), whose minimum threshold was 0.7 (Anderson and Gerbing 1988) and the variance extracted from each scale (AVE), whose value must exceed 0.5 (Fornell and Larcker 1981). All measurement scales had reliability and internal consistency indexes that were above the recommended limits (Table 4).

In the next step, we analyzed the validity of the measurement scales concluding that they obtained: (1) convergent validity because all the factor loadings were significant at 99\% ( $t$-statistic $>2.58$ ) (Steenkamp and Van Trijp 1991); and (2) discriminant validity, since the linear correlation between each pair of scales was lower than the square root of the AVE (Table 4). To analyze this type of validity more in-depth, the test of differences of $\chi^{2}=246.86(\mathrm{df}=10)$ was significant at $99 \%$ (Anderson and Gerbing 1988).

Finally, in order to check the potential problems associated with the common variance bias in the data collection, we conducted the Harman test (Podsakoff et al. 2003) by estimating a confirmatory factor analysis where all the observable variables were loaded into a single latent factor. The fit indexes obtained were $\chi_{\text {sat. }}^{2}$ $(\mathrm{df}=90)=2249.60$, RMSEA $=0.247 ; \mathrm{CFI}=0.418$; $\mathrm{IFI}=0.420$. Comparing this estimation with that of the first-order measurement model with five latent factors $\left(\Delta \mathrm{Chi}^{2}=532.23(\Delta \mathrm{df}=4), \mathrm{p}\right.$-valor $\left.<0.0001\right)$, we concluded that the single factor estimation presented a significantly worse fit.

\subsection{Estimation of mixture regression model}

To test the hypotheses, we estimated a mixture regression model. This modeling makes it possible to explain the heterogeneity that is not directly observable, among other reasons, as the heterogeneity is latent due to subjective evaluations 


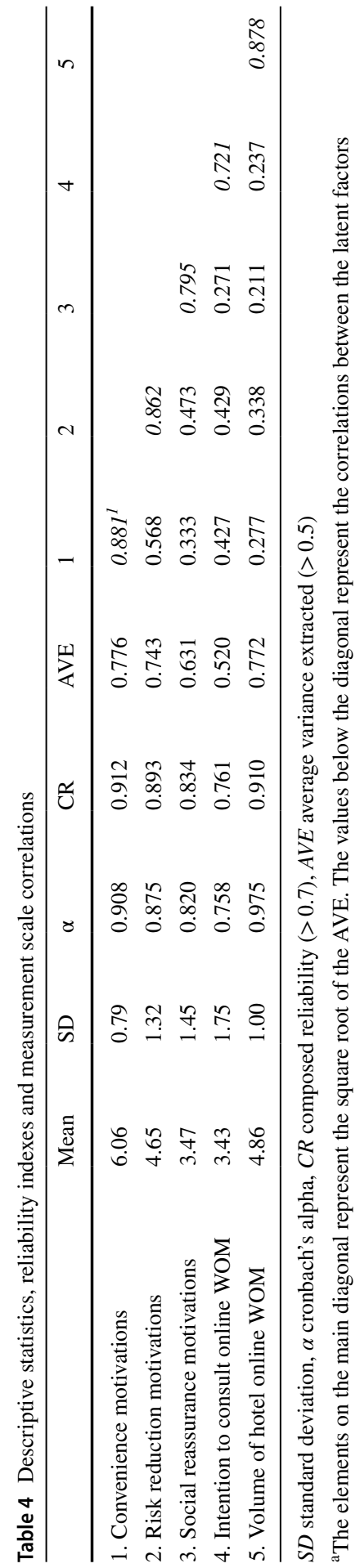


carried out by the consumer. One of the main advantages of latent modeling techniques versus deterministic techniques is that it allows defining the a priori probabilities of belonging to the segment as a function of the covariates (concomitant variables), these being the consumer's socio-demographic characteristics (Bhatnagar and Ghose 2004) or ones specific to the purchasing experience. Thus, in addition to estimating the predictors of the mixture regression model for each segment, the means of the covariables in each class were also estimated together, which is very useful to describe the segments.

In finite mixture models, it is assumed that the sample of individuals $i(i=1$, $\ldots, 393)$ comes from $S$ latent segments a priori unknown $(s=1, \ldots, S)$ in proportions, or probabilities of belonging a priori unknown $\left\{\pi_{s}\right\}_{s \in S}$. It is assumed that this probability is a function of covariates $Z_{i l}$ such as (Kamakura et al., 1994):

$$
\pi_{s \mid Z}=\frac{\exp \left(\sum_{l} \theta_{l s} Z_{i l}\right)}{\sum_{s=1}^{s} \exp \left(\sum_{l} \theta_{l s} Z_{i l}\right)}
$$

where $\theta_{l s}$ is a parameter that gathers the impact of a consumer's $l$ characteristic in the a priori probability for the latent segment $s$. Since the consumer $i$ comes from segment $s$, the intention to consult, $y_{i}$, is estimated by the vector of coefficients $\beta_{s}$, formed by the four parameters associated with the three motivations and the volume. In addition, the vector $\sigma_{s}^{\prime}$ gathers the perturbation parameters. The density function conditioned for $y$ and given $x$ y $\theta_{s}=\left(\beta_{s}^{\prime} \alpha_{s}\right)^{\prime}$ in each segment, $f\left(y \mid x, \theta_{s}\right)$, follows a normal distribution of an average $x^{\prime} \beta_{s}$ and variance $\sigma_{s}^{2}$ :

$$
f\left(y \mid x, \theta_{s}\right)=\frac{1}{\sqrt{2 \pi \sigma_{s}^{2}}} \exp \left[-\frac{\left(y-x^{\prime} \beta_{s}\right)^{2}}{2 \alpha_{s}^{2}}\right]
$$

The non-conditioned density function, that is, the model of finite mixture analysis for the $S$ segments will be given by:

$$
h(y \mid x, \Phi)=\sum_{s=1}^{S} \pi_{s} f\left(y \mid x, \theta_{s}\right)
$$

where $\Phi=\left(\pi_{s}, \theta_{s}\right)$ is the vector of population parameters for each segment $s$, $\pi_{s} \geq 0$ and $\sum_{s=1}^{S} \pi_{s}=1$. Taking into account that $\pi_{s}$ are a priori (unknown) probabilities, or a mixture of probabilities, of the segments $s=1, \ldots, S \mathrm{y}$ $\Phi=\left(\pi_{1}, \ldots, \pi_{s}, \theta_{1}, \ldots, \theta_{s}\right)$ the vector that combines all the parameters, the estimation $\widehat{\Phi}$ for the $n$ observations $\left\{\left(y_{i}, x_{i}\right)\right\}_{i=1, \ldots, 393}$ is conducted by implementing the two-stage algorithm of estimation-maximization EM (Dempster et al., 1977). Once the parameters have been obtained, the subsequent belonging probability, $\widehat{p_{i s}}$, that the consumer $i$ comes from the mixture component or the segment $s$, can be calculated for each vector $y_{i}$ : 
Table 5 Evaluation indexes for determining the number of latent classes

\begin{tabular}{llllllll}
\hline & LL & AIC & BIC & Entropy & BLRT & Size $^{\mathrm{a}}$ & $\begin{array}{l}\text { Free } \\
\text { param- } \\
\text { eters }\end{array}$ \\
\hline 1-Class & $-735,04$ & $1.482,08$ & $1.505,92$ & & & 393 & 6 \\
2-Classes & -650.70 & 1331.39 & 1391.00 & 0.771 & 0.229 & $117 / / 276$ & 15 \\
3-Classes & $\mathbf{- 6 0 6 . 4 1}$ & $\mathbf{1 2 6 0 . 8 3}$ & $\mathbf{1 3 5 6 . 2 0}$ & $\mathbf{0 . 8 3 1}$ & $\mathbf{0 . 0 2 8}$ & $\mathbf{1 1 2 / / 1 7 4 / / 1 0 7}$ & $\mathbf{2 4}$ \\
4-Classes & -584.50 & 1235.01 & 1366.14 & 0.815 & 0.080 & $11 / / 161 / / 115 / / 106$ & 33 \\
5-Classes & -574.68 & 1233.35 & 1400.25 & 0.809 & 0.010 & $106 / / 11 / / 18 / / 156 / / 102$ & 42 \\
\hline
\end{tabular}

$L L$ log-likelihood, AIC akaike information criteria, BIC bayesian information criteria, BLRT parametric bootstrap likelihood ratio test

${ }^{\text {a }}$ Segment size is the probability estimated of belonging shown in Eqs. 2 and 3

$$
\widehat{p_{i s}}=\frac{f_{s}\left(y \mid x, \widehat{\theta}_{s}\right) \hat{\pi}_{s}}{\sum_{s=1}^{S} f_{s}\left(y \mid x, \hat{\theta}_{s}\right) \hat{\pi}_{s}}
$$

The estimation of subsequent probabilities, $\widehat{p_{i s}}$, can be used to classify each individual $i$, in the segment $s$, by assigning the observation to the class in which it subsequently presents the highest probability. In addition, the subsequent probabilities determine the estimation of the regression parameters for each segment.

\section{Results}

\subsection{Determination of the number of latent segments}

The estimation of the mixture regression model was carried out using Mplus 8.0. Following the notation explained in Sect. 3.3, it is assumed that, from $i=1, \ldots, 393$ individuals, there exist $\mathrm{s}=1, \ldots \mathrm{S}$ latent segments a priori unknown. We made the model estimations based on $S=1$ (no heterogeneity exists) up to $S=5$ segments or classes, initially using gender, age, type of trip, frequency of stay in the hotel, level of studies and nationality as covariates. Only the parameters associated with age, frequency of stay and studies were significant, so these were included in the final estimations.

The choice of the number of segments to be retained was made in accordance with a combination of theoretical and practical criteria (McLachlan and Peel 2000). Table 5 shows the values of the maximum likelihood logarithm together with the main fit indexes.

The solutions of 4 and 5 latent segments had a lower AIC value, although it was the 3-segment solution that has the lowest BIC value. This solution showed better discriminatory capacity, according to the entropy index, closer to 1 . In addition, taking into account the results of the simulation carried out by Nylund et al. (2007), the BLRT value also pointed to the suitability of this solution. Finally, we can mention 
that in the 3 latent segments solution, the average probability of belonging to the most probable class exceeded $85 \%$ (class $_{1}=0.953$, class $_{2}=0.921 ;$ class $_{3}=0.890$ ), with highly satisfactory results. Thus, the estimation of the model with 3 classes or latent segments was retained as the best solution.

\subsection{Results of the mixture regression model}

The results regarding the global model's solution (without considering the heterogeneity) indicate that the three motivations for consulting comments have a positive and significant effect on the intention of consultation (Table 6), where risk reduction was the main driver. These results allow us to confirm the first group of hypotheses $\left(\mathrm{H}_{1 \mathrm{a}}, \mathrm{H}_{1 \mathrm{~b}}\right.$ and $\left.\mathrm{H}_{1 \mathrm{c}}\right)$. The model estimation that did not consider the unobserved heterogeneity did not show that intentions depended to any extent on the volume of comments, so $\mathrm{H}_{2}$ could not be confirmed.

Based on the estimate coefficients associated to the four independent constructs, the results of the mixture regression model indicate that the influence of the motivations and the volume of comments vary according to the three identified segments (Table 6). The convenience motivation had a significant impact on the intention to consult in two segments and was not significant in the second class. Similarly, the risk reduction motivation had a significant influence on two segments only. Social reassurance motivations did have a positive and significant impact both in the global model and throughout the three classes, although they had a greater weight in the first segment. Overall, these results confirm the third group of hypotheses $\left(\mathrm{H}_{3 a}, \mathrm{H}_{3 \mathrm{~b}}\right.$ and $\mathrm{H}_{3 \mathrm{c}}$ ). Similar discrepancies also occurred in relation to the influence of the volume of comments, since it had a significant influence on the first segment only, confirming $\mathrm{H}_{4}$.

The results described show that there were substantial differences in the estimations between the global model and those of the finite mixture model. Such differences also affect the explained variability, since the $\mathrm{R}^{2}$ of the three latent classes was much higher than that obtained for the global model. Based on the above, we can affirm the existence of heterogeneity regarding consultation intentions determined by the motivations and the volume of comments. To study the final composition of the three latent classes, the information from all the descriptive variables initially used as covariates was analyzed. (Table 7).

Segment 1 ("the motivated") was mainly characterized by the influence of the three motivations on consultation intentions, notably the effect of risk reduction and social reassurance motivations. Segment 1 was the only segment where the number of hotel comments had significant and negative effects. This group stood out for being the oldest in age, with the lowest level of education, the highest percentage of Spaniards with respect to the rest of the groups and with the lowest rate of hotel stay frequency. This segment also shows the highest percentage of guests staying in 4 and 5-star hotels.

Segment 2 ("the social reassurance" group) was the largest group. It was characterized by the influence of motivations associated with social influence, such as risk reduction and social reassurance, although effects were lower than for Segment 


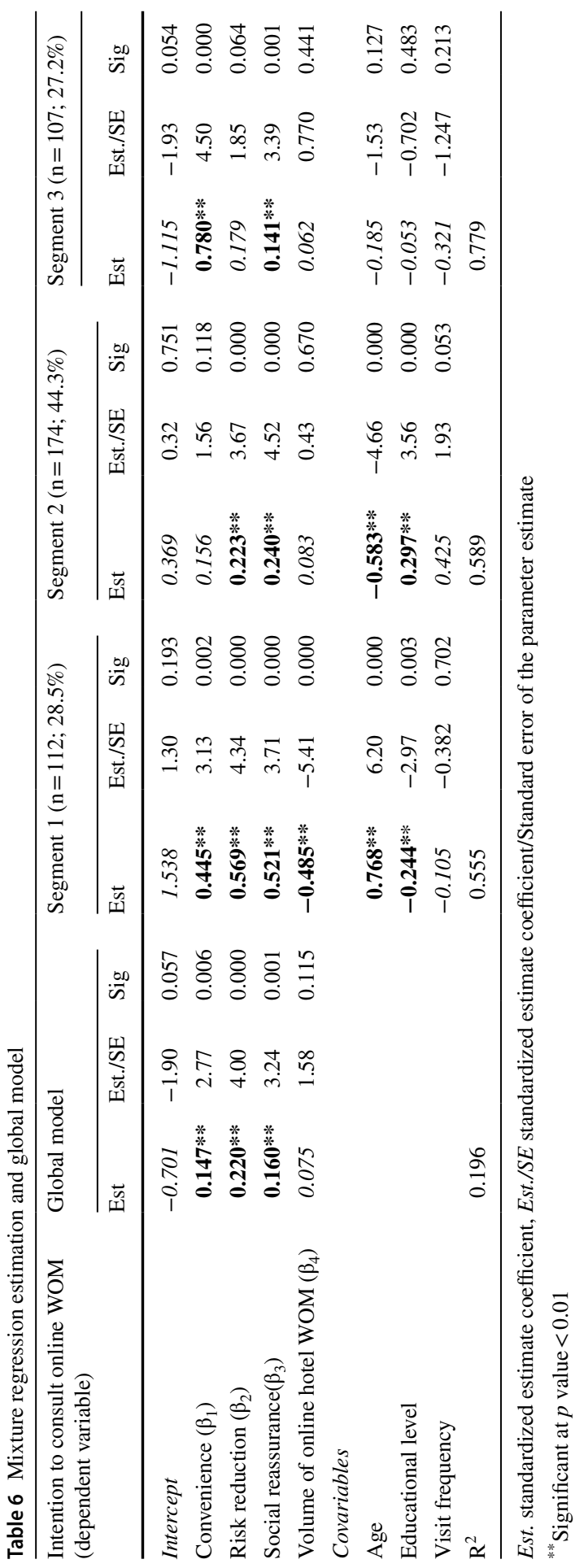


Table 7 Latent segments profile

$\begin{array}{llll}\begin{array}{l}\text { Global } \\ (\mathrm{n}=393)\end{array} & \begin{array}{l}\text { Segment 1 } \\ (\mathrm{n}=112)\end{array} & \begin{array}{l}\text { Segment 2 } \\ (\mathrm{n}=174)\end{array} & \begin{array}{l}\text { Segment 3 } \\ (\mathrm{n}=107)(\%)\end{array} \\ (\%) & (\%) & (\%) & \end{array}$

Gender $\chi^{2}(\mathrm{df}=2)=0.42(p$ value $=0.812)$

\section{Male}

Female

Age $\chi^{2}(\mathrm{df}=10)=91.52 * *(p$ value $<0.0001)$

$$
\begin{aligned}
& 18-25 \text { years } \\
& 26-35 \text { years } \\
& 36-45 \text { years } \\
& 46-55 \text { years } \\
& 56-65 \text { years } \\
& >65 \text { years }
\end{aligned}
$$

Trip purpose $\chi^{2}(\mathrm{df}=4)=2.54(p$ value $=0.638)$

$$
\text { Leisure }
$$

Business

Others

Visit frequency $\chi^{2}(\mathrm{df}=4)=\mathbf{2 0 . 8 2} * *(p$ value $<0.0001)$

At least once a year

2-4 times/year

More than 4

Nationality $\chi^{2}(\mathrm{df}=10)=15.73(p$ value $=0.108)$

$$
\text { Spanish }
$$

British

French

Italian

US

Others

Educational level $\chi^{2}(\mathrm{df}=16)=\mathbf{7 2 . 3 6}^{* *}(p$ value $<0.0001)$

No studies

Primary studies

Secondary studies

Vocational training 1

Vocational training 2

3-year degree

5-year degree

Postgraduate studies

Others

$\begin{array}{rccc}46.6 & 47.32 & 47.70 & 43.93 \\ 53.4 & 52.68 & 52.30 & 56.07 \\ & & & \\ 10.9 & 1.79 & 13.22 & 16.82 \\ 19.3 & 8.04 & 22.99 & 25.23 \\ 29.5 & 21.43 & 31.61 & 34.58 \\ 19.8 & 23.21 & 20.11 & 15.89 \\ 11.7 & 19.6 & 9.2 & 7.5 \\ 8.7 & 25.9 & 2.9 & 0.0\end{array}$

$\begin{array}{rrrr}89.6 & 90.18 & 90.80 & 86.92 \\ 8.1 & 8.04 & 6.32 & 11.21 \\ 2.3 & 1.79 & 2.87 & 1.87\end{array}$

$\begin{array}{llll}44.0 & 59.82 & 32.76 & 45.79 \\ 36.1 & 27.68 & 42.53 & 34.58 \\ 19.8 & 12.50 & 24.71 & 19.63\end{array}$

$\begin{array}{llll}88.5 & 92.86 & 86.78 & 86.92\end{array}$

$\begin{array}{llll}1.8 & 0.00 & 1.72 & 3.74\end{array}$

$\begin{array}{llll}1.5 & 0.89 & 2.30 & 0.93\end{array}$

$\begin{array}{llll}1.5 & 0.00 & 2.87 & 0.93\end{array}$

$\begin{array}{llll}0.5 & 1.79 & 0.00 & 0.00\end{array}$

$\begin{array}{llll}6.1 & 4.46 & 6.32 & 7.48\end{array}$

$\begin{array}{rccc}1.8 & 5.36 & .6 & 0.0 \\ 13.7 & 32.14 & 6.90 & 5.61 \\ 15.3 & 15.18 & 13.79 & 17.76 \\ 7.1 & 7.14 & 5.75 & 9.35 \\ 11.5 & 11.61 & 9.77 & 14.02 \\ 14.8 & 8.93 & 17.2 & 16.8 \\ 33.1 & 18.75 & 41.38 & 34.58 \\ 2.0 & .9 & 2.9 & 1.9 \\ 0.8 & 0.00 & 1.72 & 0.00\end{array}$


1. Segment 2 was the only group to be unaffected by convenience motivation. This group included the most adults, the highest level of studies, the most foreign consumers and the highest rate of hotel stay frequency compared to the other groups. This segment also shows the highest percentage of guests staying in 3-star hotels.

Finally, segment 3 ("the practical" group) was mainly characterized by the notable effect of convenience on the intention to consult. Social reassurance motivations also had a significant influence, but risk reduction did not. This group was the youngest in age, included a larger number of women and business guests.

\section{Discussion and conclusion}

\subsection{Theoretical contribution}

The literature on online WOM behavior showed that significant gaps remain at conceptual and operational levels. This poses interesting challenges to further examine receiver viewpoint and to develop a segmentation approach. This work has sought to contribute to this research line in the hospitality sector. It presents results on the factors that influence online comment consultations and on the differences between these relationships as a consequence of the unobserved heterogeneity of consumers.

First, this study contributed to existing literature as the specific motivations for reviewing online WOM on hotels were examined. Although some empirical evidence exists on the type of motivations that prompt consumers to consult the most (Parikh et al. 2014), no contributions have been found on the causal relationship between motivations and the intention to consult online WOM. An interesting finding of this study is that consumer convenience, risk reduction and social reassurance motivations play an important role in the intentions to consult. Further motivations related to risk reduction were among the most relevant. The price of staying in a hotel, the variability of the service or the difficulty of making a prior evaluation (Lin 2008; Parikh et al. 2014) can be compelling reasons that increase the perception of the risk associated with the purchase of this type of service. This very risk motivates consumers to look for online comments that help them to reduce their decision's probability of failure. Therefore, though other factors beyond individual ones can influence the intention to consult online WOM (e.g. presentation of information, media where it is published, who has written the comment, etc.), the results revealed that consultation behaviors largely depended on the individual's personal characteristics and especially on their motivations.

Another important finding from this study is that the intention to consult online WOM does not depend on the volume of the hotel's online comments. The amount of information can increase consumer trust because it is perceived as more objective and useful in the purchasing process (Yen and Tang 2015; Park and Lee 2009). However, a possible explanation for this absence of relationship can be found in the theory of Petty and Cacioppo (1986) on consumers' choice of central or peripheral routes. Given that an accommodation service is a complex, high-risk decision that requires some involvement on the part of the future customer, it is assumed that the customer will choose the 
central route when making a decision and will be more influenced by the quality of the consulted information than by the quantity.

Second, with regard to market heterogeneity, the limited contributions on segmentation that explain online WOM focus on this behavior from the sender perspective (e.g. Xiang et al. 2017; Wu et al. 2017; Dowell and Turner 2019) and adopting an observed heterogeneity approach (e.g. Wu et al. 2017; Xu 2018). Thus, our methodology makes a step forward in this line of research since we estimated a regression mixture model to analyze the unobserved heterogeneity. Furthermore, our findings are up-to-date and novel in this field of study, in cases where consumers differ based on their online WOM inquiries. In particular, the effects of motivations and volume of online hotel WOM on the intention to consult varied according to groups of consumers. The methodology adopted allowed us to identify three latent segments that were variously influenced by the variables.

The first was the group formed by "motivated" consumers where the three types of motivations and the volume of the hotel's WOM played a major role. The greater number of motivations and the lower the perceived volume of comments on the hotel, the greater the intention to consult. The negative influence of the volume could reinforce the positive effect of the convenience motivation, since the perception of a high volume of comments could be understood as poorly operational, not making the hotel selection process more agile nor more comfortable. This result is compatible with Furner et al. (2016) who confirmed that trust in the comments was reduced when there was a high volume of comments. This fact can be related to the problem of the "democratization of opinions" resulting today from excessive and unfiltered dissemination of online comments (Litvin et al. 2018).

Second, "the social reassurance" segment were consumers who were mainly driven by risk reduction and social reassurance when conducting online consultations. The fact that they knew the hotels the best may explain the fact that convenience motivations did not exert any influence on the intention to consult. This means that the degree of knowledge of the establishment derived from the frequency of visits can reduce motivations linked to the convenience or speed of purchase. Therefore, these aspects may not play a major role in the case of consumers with a certain degree of loyalty to the hotel.

And finally, "the practical" group was the segment for which convenience motivations were the most decisive factor regarding intentions to consult. The advantages of convenience, speed or immediacy of the consultations seemed to be especially associated with younger consumers, the female gender and business stay hotel searches. In addition, this group was the least influenced by social reassurance motivations. Although the social component was very present in the motivations to write online WOM (Munar and Jacobsen 2014), the sense of belonging to the group or the desire to participate in it did not seem to weigh on the consultations of this group of consumers.

\subsection{Practical implications}

From a practical perspective, the results of this work can be used by hotel managers in a number of ways. First, promotion and customer attraction strategies should 
focus more on the motivations underlying the reading of hotel reviews. We dispose of empirical evidence in the tourism sector that consultations influence choice decisions (Fakharyan et al. 2012). Our results further confirm that convenience, risk reduction and social motivations encourage consumers to seek hotel reviews. Therefore, it would be interesting for hotels to improve their search systems and facilitate consumers access to information about other consumers' experiences.

Secondly, online reviews about hotels are not homogeneous. Motivations to consult vary depending on consumer profiles. This implies that it is necessary to design communication strategies more efficiently, that is, adapt them according to the hotel's target in terms of: socio-demographic characteristics (e.g. retirees, families, youth, etc.), type of customer (e.g. regular or occasional customer) and type of stay or establishment (e.g. hotel for business clients, sun and beach hotels, countryside hotels, cultural tourism hotel, etc.). Considering these hotel target characteristics, managers should direct their actions according to the aspect they are interested in improving, one type of motivation or another, or the perception of the volume of comments on their hotel.

For example, if the hotel's target audience is the national senior consumer market (Segment 1: "the motivated" group), it would be effective to influence different motivations, improving the perceptions of time saving, comfort, purchase risk or belonging to a group with the same interests. In the same way, it would also be advisable to change the perception of the hotel's volume of comments for this segment, for example, establishing filters that limit the number of not very useful comments, or acting on the comments of "terrorist customers". If the hotel's target is foreign, educated, more loyal customers (Segment 2: "the social reassurance" group), it would be convenient to improve the communication aspects with similar customer profiles since this group is particularly motivated by the social context and the opinions of others. And finally, if the hotel's target is business travelers (Segment 3: "the practical" group), it would be interesting to focus efforts on the practical aspects of information searching such as speed, comfort or ease of hotel data comparison.

\subsection{Limitations and future research}

Some methodological and conceptual improvements are now proposed to advance in this line of research.

First, concerning methodology, it would be interesting to study the online WOM consultations in other accommodation services (e.g. accommodation exchange, tourist apartment rentals, campsites, the airbnb platform, etc.). This analysis would allow to verify, on the one hand, whether the motivations and the volume of comments maintain the same levels of influence on the intention to consult WOM, and, on the other hand, to know whether consumers also present heterogeneity. Secondly, to be able to generalize the results at the national level, the sample could also be extended to other geographical areas, thus helping to improve the profile of the segments.

At the conceptual level, since the motives driving people to consult WOM have received much less attention than the drivers of WOM writing (Munzel and Kunz 2014), further empirical research on online WOM seekers' motivations is needed 
to further explore the reasons for and consequences of online WOM behavior. Furthermore, WOM behavior could be researched from the joint sender and receiver perspective. If consumers use online WOM consultations to make their purchase decision, this information can generate expectations that can influence their level of satisfaction, and this satisfaction would increase the likelihood of engaging in online WOM about their experience (Jani and Han 2014). Therefore, studying the motivations of individuals who consult comments to make purchasing decisions and the motivations of individuals who write and disseminate comments about their experience will not only differentiate both behaviors but also identify common precedents or possible relationships between them. In this line of dual receiver-sender research, it would be interesting to evaluate the possible effect that the number of stars or the category of accommodation may have on online WOM.

Finally, the COVID-19 global pandemic has generated a business crisis that especially affects the hospitality sector. This situation has led to certain changes in the pre-purchasing phase, such as new decision criteria (e.g. open spaces, security measures) or less impulsive purchase. These changes may modify online WOM search, so it is necessary to study other variables that may influence consumer motivations or may play an important role in online inquiries. For example, WOM information credibility has recently been found to be a highly influential factor in purchase decisions (Levy and Gvili 2015; Rahman and Mannan 2018), so we understand this variable as a potential driver of WOM search. Moreover, in today's tourism sector crisis, where consumers are more rational and adopt new criteria in their purchase decisions, examining consumer commitment to online WOM may be of particular interest. This type of commitment, based on the desire to request or share information from or with other consumers, respectively (Yusuf et al. 2018), has been poorly researched. Learning more about this variable could help advance the study of online WOM reviews.

Acknowledgements The authors are grateful for the support from project ECO2016-76553-R from the Spanish Ministry of Education and Science.

\section{References}

Abrantes JL, Seabra C, Lages CR, Jayawardhena C (2013) Drivers of in-group and out-of-group electronic word-of-mouth (eWOM). Eur J Mark 47(7):1067-1088

AIMC (2018) 20 a Encuesta AIMC a usuarios de Internet - Navegantes en la Red. http://download.aimc. es/aimc/ARtu5f4e/Infografia_naveg_20.pdf. Accessed Jan 92019.

Anderson EW (1998) Customer satisfaction and word of mouth. J Serv Res 1(1):5-17

Anderson JC, Gerbing DW (1988) Structural equation modeling in practice: a review and recommended two-step approach. Psychol Bull 103(3):411-423

Baber A, Thurasamy R, Malik MI, Sadiq B, Islam S, Sajjad M (2016) Online word-of-mouth antecedents, attitude and intention-to-purchase electronic products in Pakistan. Telemat Inform 33(2):388-400

Bachleda C, Berrada-Fathi B (2016) Is negative eWOM more influential than negative WOM? J Serv Theor Pract 26(1):109-132

Belanche D, Casaló L, Guinaliú M (2013) Comunicación comercial y boca-oído electrónico en sitios web corporativos: un análisis desde la perspectiva del marketing de relaciones. Investigaciones Europeas de Dirección y Economía de la Empresa 19:31-41 
Berezan O, Raab C, Tanford S, Kim YS (2015) Evaluating loyalty constructs among hotel reward program members using eWOM. J Hospit Tourism Res 39(2):198-224

Bhatnagar A, Ghose S (2004) Segmenting consumers based on the benefits and risks of Internet shopping. J Bus Res 57:1352-1360

Bigné E, Ruiz C, Andreu L, Hernández B (2015) The role of social motivations, ability, and opportunity in online know-how exchanges: evidence from the airline services industry. Serv Bus 9:209-232

Blal I, Sturman MC (2014) The differential effects of the quality and quantity of online reviews on hotel room sales. Cornell Hospit Q 55(4):365-375

Boo S, Kim J (2013) Comparison of negative eWOM intention: an exploratory study. J Qual Assur Hospit Tourism 14(1):24-48

Buzova D, Sanz-Blas S, Cervera-Taulet A (2019) Does culture affect sentiments expressed in cruise tours' eWOM? Serv Ind J 39(2):154-173

Carballo RR, León CJ, Carballo MM (2017) The perception of risk by international travelers. Worldwide Hospit Tourism Themes 9(5):534-542

Casado-Díaz AB, Pérez-Naranjo LM, Sellers-Rubio R (2017) Aggregate consumer ratings and booking intention: the role of brand image. Serv Bus 11:543-562

Casaló L, Flavian C, Guinaliu M, Ekinci Y (2015) Do online hotel rating schemes influence booking behaviors? Int J Hospit Manag 49:28-36

Chan YYY, Ngai EWT (2011) Conceptualising electronic word of mouth activity. An input-process-output perspective. Market Intell Plann 29(5):488-516

Chiang C, Jang S (2006) The effects of perceived price and brand image on value and purchase intention: Leisure travelers' attitudes toward online hotel booking. J Hospit Leisure Market 15(3):49-69

Correia Loureiro SM, Gorgus T, Kaufmann HR (2017) Antecedents and outcomes of online brand engagement. The role of brand love on enhancing electronic-word-of-mouth. Online Inform Rev 41(7):985-1005

Davis A, Khazanchi D (2008) An empirical study of online word of mouth as a predictor for multi-product category e-commerce sales. Electron Markets 18(2):130-141

Dempster AP, Laird NM, Rubin DB (1977) Maximum likelihood from incomplete data via the EM algorithm. J Royal Statist Soc Series 39(1):1-38

Dowell D, Garrod B, Turner J (2019) Understanding value creation and word-of-mouth behaviour at cultural events. Serv Ind J 39(7-8):498-518

Fakharyan M, Jalilvand MR, Elyasi M, Mohammadi M (2012) The influence of online word of mouth communications on tourists' attitudes toward Islamic destinations and travel intention: evidence from Iran. Afr J Bus Manage 6(38):10381-10388

Filieri R, McLeay F (2013) E-WOM and accommodation: an analysis of the factors that influence travelers' adoption of information from online reviews. J Travel Res 53(1):44-57

Fine MB, Gironda J, Petrescu M (2017) Prosumer motivations for electronic word-of-mouth communication behaviors. J Hospit Tourism Technol 8(2):280-295

Flanagin AJ, Metzger MJ, Pure R, Markov A, Hartsell E (2014) Mitigating risk in ecommerce transactions: perceptions of information credibility and the role of usergenerated ratings in product quality and purchase intention. Electron Commer Res 14(1):1-23

Fornell C, Larcker DF (1981) Evaluating structural equation models with unobservable variables and measurement error. J Mark Res 28(February):39-50

Furner CP, Zinko R, Zhu Z (2016) Electronic word-of-mouth and information overload in an experiential service industry. J Serv Theor Pract 26(6):788-810

Gelbrich K (2011) I have paid less than you! The emotional and behavioral consequences of advantaged price inequality. J Retail 87(2):207-224

Goldsmith RE, Horowitz D (2006) Measuring motivations for online opinion seeking. J Interact Advert 6(2):1-16

Goyette I, Ricard L, Bergeron J, Marticotte F (2010) E-WOM scale: word-of-mouth measurement scale for e-services context. Canad J Adm Sci 27:5-23

Gremler DD, Brown SW (1999) The loyalty ripple effect: appreciating the full value of customers. Int J Serv Indus Manag 10(3):271-291

Gruen TW, Osmonbekov T, Czaplewski AJ (2006) eWOM: the impact of customer-to-customer online know-how exchange on customer value and loyalty. J Bus Res 59:449-456

Gupta P, Harris J (2010) How e-WOM recommendations influence product consideration and quality of choice: a motivation to process information perspective. J Bus Res 63(9/10):1041-1049

Hair JFJr, Anderson RE, Tatham RL, Black WC (2008) Análisis multivariante. Prentice Hall, Madrid 
Harrison-Walker LJ (2001) The measurement of word-of-mouth communication and an investigation of service quality and customer commitment as potential antecedents. J Serv Res 4(1):60-75

Hennig-Thurau T, Walsh G (2003) Electronic word-of-mouth: Motives for and consequences of reading customer articulations on the Internet. Int J Electron Commer 8:51-74

Hennig-Thurau T, Gwinner KP, Walsh G, Gremler DD (2004) Electronic word-of-mouth via consumeropinion platforms: what motivates consumers to articulate themselves on the internet? J Interact Market 18(1):38-52

Hu Y, Kim HJ (2018) Positive and negative eWOM motivations and hotel customers' eWOM behavior: does personality matter? Int J Hosp Manag 75:27-37

Jani D, Han H (2014) Personality, satisfaction, image, ambience, and loyalty: testing their relationships in the hotel industry. Int J Hosp Manag 37:11-20

Kamakura WA, Wedel M, Agrawal J (1994) Concomitant-variable latent class models for conjoint analysis. Int J Res Mark 11(5):451-564

Kaplowitz SA, Fink EL, Dalessio D, Armstrong GB (1983) Anonymity, strength of attitude, and the influence of public-opinion polls. Human Commun Res 10(1):5-25

Kim DH, Jang SCS (2019) The psychological and motivational aspects of restaurant experience sharing behavior on social networking sites. Serv Bus 13:25-49

Kim EEK, Lee CH (2015) How do consumers process online hotel reviews? The effects of eWOM consensus and sequence. J Hosp Tour Technol 6(2):113-126

Kim EEK, Mattila AS, Baloglu S (2011) Effects of gender and expertise on consumers' motivation to read online hotel reviews. Cornell Hosp Q 52(4):399-406

King RA, Racherla P, Bush VD (2014) What we know and don't know about online word-of-mouth: a review and synthesis of the literature. J Interact Market 28(3):167-183

Laughlin JD, MacDonald JB (2010) Identifying market mavens online by their social behaviors in community-generated media. Acad Market Stud J 14(1):55-70

Lee HA, Law R, Murphy J (2011) Helpful reviewers in TripAdvisor, an online travel community. J Travel Tour Market 28(7):675-688

Leung XY, Bai B, Stahura KA (2015) The marketing effectiveness of social media in the hotel industry: a comparison of facebook and twitter. J Hosp Tour Res 39(2):147-169

Levy S, Gvili Y (2015) How credible is e-word of mouth across digital-marketing channels? The roles of social capital, information richness, and interactivity. J Advert Res 55(1):95-109

Lin WB (2008) Investigation on the model of consumers' perceived risk - integrated viewpoint. Expert Syst Appl 34(2):977-988

Lin C, Xu X (2017) Effectiveness of online consumer reviews: the influence of valence, reviewer ethnicity, social distance and source trustworthiness. Internet Res 27(2):362-380

Litvin SW, Goldsmith RE, Pan B (2008) Electronic word-of-mouth in hospitality and tourism management. Tour Manag 29(3):458-468

Litvin SW, Ronald E, Goldsmith BP (2018) A retrospective view of electronic word-of-mouth in hospitality and tourism management. Int J Contemp Hosp Manag 30(1):313-325

Liu Y, Teichert T, Rossi M, Li H, Hu F (2017) Big data for big insights: investigating language-specific drivers of hotel satisfaction with 412,784 user-generated reviews. Tour Manag 59:554-563

Matute-Vallejo J, Polo-Redondo Y, Utrillas-Acerete A (2015) Las características del boca-oído electrónico y su influencia en la intención de recompra online. Revista Europea de Dirección y Economía de la Empresa 24:61-75

Matute-Vallejo J, Polo-Redondo P, Utrillas-Acerete A (2016) The influence of EWOM characteristics on online repurchase intention Mediating roles of trust and perceived usefulness. Online Inform Rev 40(7):1090-1110

Maxham JG III, Netemeyer RG (2002) A longitudinal study of complaining customers' evaluations of multiple service failures and recovery efforts. J Market 66:57-71

Mazzarol T, Sweeney JC, Soutar GN (2007) Conceptualizing word-of-mouth activity, triggers and conditions: an exploratory study. Eur J Mark 41(11/12):1475-1494

McLachlan G, Peel D (2000) Finite mixture models. John Wiley and Sons Inc, New York

Meuter ML, McCabe DB, Curran JM (2013) Electronic word-of-mouth versus interpersonal word-ofmouth: are all forms of word-of-mouth equally influential? Serv Market Q 34(3):240-256

Mitchell VW, Greatorex M (1989) Risk reducing strategies used in the purchase of wine in the UK. Eur J Mark 23(9):31-46

Moliner-Velázquez B, Fuentes-Blasco M, Gil-Saura I (2019) The role of ICT, eWOM and guest characteristics in loyalty. J Hosp Tour Technol 10(2):153-168 
Munar AM, Jacobsen JKS (2014) Motivations for sharing tourism experiences through social media. Tour Manag 43:46-54

Munzel A, Kunz WH (2014) Creators, multipliers, and lurkers: who contributes and who benefits at online review sites. J Ser Manag 25(1):49-74

Nylund KL, Asparouhov T, Muthén B (2007) Deciding on the number of classes in latent class analysis and growth mixture modeling: A Monte Carlo simulation study. Struct Equ Model 14(1):535-569

O'Connor P (2009) Pay-per-click search engine advertising: Are hotel trademarks being abused? Cornell Hosp Q 50(2):232-244

Parikh A, Behnke C, Vorvoreanu M, Almanza B, Nelson D (2014) Motives for reading and articulating user-generated restaurant reviews on Yelp. com. J Hosp Tour Technol 5(2):160-176

Park C, Lee TM (2009) Information direction, website reputation and eWOM effect: a moderating role of product type. J Bus Res 62(1):61-67

Park DH, Lee J, Han I (2007) The effect of online consumer reviews on consumer purchasing intention: the moderating role of involvement. Int J Electron Commer 11(4):125-148

Petty RE, Cacioppo JT (1986) Communication and Persuasion: Central and Peripheral Routes to Persuasion. Springer, New York

Podsakoff PM, MacKenzie SB, Lee Y, Podsakoff NP (2003) Common method biases in behavioral research: a critical review of the literature and recommended remedies. J Appl Psychol 88(5):879-903

Rahman MS, Mannan M (2018) Consumer online purchase behavior of local fashion clothing brands. Information adoption, e-WOM, online brand familiarity and online brand experience. J Fashion Market Manag 22(3):404-419

Rani A, Shivaprasad HN (2018) Determinants of electronic word of mouth persuasiveness. A conceptual model and research propositions. J Contemp Manag Res 12(2):1-16

Schiffman LG, Kanuk LL (1978) Consumer behavior. Prentice Hall, Englewood Cliffs New Jersey

Serra-Cantallops A, Salvi F (2014) New consumer behavior: a review of research on eWOM and hotels. Int J Hosp Manag 36:41-51

Shen W, Huang J, Li D (2016) The research of motivation for word-of-mouth: based on the self-determination theory. J Bus Retail Manag Res 10(2):75-84

Silverman G (2001) Secrets of Word-of-Mouth Marketing. AMACOM Books, New York

Smith GE, Venkatraman MP, Dholakia RR (1999) Diagnosing the search cost effect: waiting time and the moderating impact of prior category knowledge. J Econ Psychol 20(3):285-314

Song B, Lee C, Yoon B, Park Y (2016) Diagnosing service quality using customer reviews: an index approach based on sentiment and gap analyses. Ser Bus 10:775-798

Srivastava JC, Soutar GN, Mazzarol T (2018) Motivations and outcomes of seeking online consumer reviews: a literature synthesis. J Consum Satisfact Dissatisfact Complain Behav 31:1-30

Steenkamp EM, Van Trijp CM (1991) The Use of LISREL in Validating Marketing Constructs. Int J Res Mark 8(4):283-299

Sun T, Youn S, Wu G, Kuntaraporn M (2006) Online word-of-mouth (or mouse): an exploration of its antecedents and consequences. J Comp-Mediat Commun 11:1104-1127

Sweeney JC, Soutar GN, Mazzarol T (2008) Factors influencing word of mouth effectiveness: receiver perspectives. Eur J Mark 42(3/4):344-364

Sweeney JC, Soutar GN, Mazzarol T (2012) Word of mouth: measuring the power of individual messages. Eur J Mark 46(1/2):237-257

Terblanche NS (2016) Measuring word-of-mouth activity after a service encounter: are we measuring what customers communicate? Serv Bus 10:283-299

Theng G, Ng S (2001) Individual and situational factors influencing negative word-of-mouth behavior. Canad J Adm Sci 18(3):163-178

Tsiotsou RH, Mild A, Sudharshan D (2012) Social interactions as basis for segmenting the tourism market. In: Tsiotsou RH, Goldsmith RE (eds) Strategic Marketing in Tourism Services. Bingley, Emerald, pp 35-48

UNWTO (2018) Tourism highlights. https://www.e-unwto.org/doi/pdf/https://doi.org/10.18111/97892 84419876. Accessed Jan 9201.

Wang KC, Chou SH, Su CJ, Tsai HY (2007) More information, stronger effectiveness? Different group package tour advertising components on web page. J Bus Res 60(4):382-387

Westbrook RA (1987) Product/consumption-based affective responses and postpurchase processes. J Mark Res 24(3):258-270 
WOMMA (2014) Return of word of mouth. https://womma.org/free-womm-resources/. Accessed May 5 2017.

Wu L, Shen H, Fan A, Mattila AS (2017) The impact of language style on consumers reactions to online reviews. Tour Manag 59:590-596

Xiang Z, Du Q, Ma Y, Fan W (2017) A comparative analysis of major online review platforms: implications for social media analytics in hospitality and tourism. Tour Manag 58:51-65

Xu X (2018) Does traveler satisfaction differ in various travel group compositions?: evidence from online reviews. Int J Contemp Hosp Man 30(3):1663-1685

Xu X, Li Y (2016) The antecedents of customer satisfaction and dissatisfaction toward various types of hotels: a text mining approach. Int J Hosp Manag 55:57-69

Yeap J, Ignatius J, Ramayah Y (2014) Determining consumers' most preferred EWOM platform for movie reviews: a fuzzy hierarchy process approach. Comput Hum Behav 31(1):250-258

Yen CL, Tan CH (2019) The effects of hotel attribute performance on electronic word-of-mouth (eWOM) behaviors. Int J Hosp Manag 76:9-18

Yen CL, Tang CH (2015) Hotel attribute performance, eWOM motivations, and media choice. Int J Hosp Manag 46:79-88

Yusuf AS, Razak A, Hussin C, Busalim AH (2018) Influence of e-WOM engagement on consumer purchase intention in social commerce. J Serv Mark 32(4):493-504

Zhao X, Sun YS, Wang L, Guo X, Law R (2015) The influence of online reviews to online hotel booking intentions. Int J Contemp Hosp Manag 27(6):1343-1364

Zhu F, Zhang X (2010) Impact of online consumer reviews on sales: the moderating role of product and consumer characteristics. J Market 74(March):133-148

Zhu L, Yin G, He W (2014) Is this opinion leader's review useful? peripheral cues for online review helpfulness. J Electron Commer Res 15(4):267-280

Publisher's Note Springer Nature remains neutral with regard to jurisdictional claims in published maps and institutional affiliations. 